\title{
PENGARUH PELATIHAN DAN PENDIDIKAN TERHADAP KINERJA PENYULUH PERTANIAN PADA BKP5K KABUPATEN BOGOR
}

\author{
Herty Ramayanti Sinaga \\ Herty.ramayanti@piksi-ganesha-online.ac.id \\ Politeknik Piksi Ganesha
}

\begin{abstract}
One way to improve the quality of agricultural extension resource through education and training is implemented out in a planned and systematic. In other words, the importance of education and training within the organization is to improve the performance of agricultural extension that include the knowledge and skill that support, as well as the building of the attitude of each of the extension as desired by organization. This study aims to analyze the influence of training and education on the performance of agricultural extension workers in the Food Security and Managing Extension Agriculture, Fisheries and Forestry (BKP5K) Bogor and analyze the indicators that reflect the dominant success of the training and education provided to the agricultural extension. Sampling is based on non-probability sampling technique using purposive sampling method of 79 samples from 99 populations of agricultural extension agricultural extension PNS. These results indicate that 1) the influence of training and education on the performance of agricultural extension, the training negatively affect the performance of agricultural extension and education have positive influence on the performance of agricultural extension; and 2) the dominant indicator of the training variables contained in the first indicator, namely the training suitability of the materials needed with this type of training with the results of 3.28. Dominant indicator of educational variables contained in the second indicator, namely the educational suitability of the current work with the results of 3.28. Dominant indicator of performancel variables contained in the first indicator, namely understand the program with the results of 3.23 .
\end{abstract}

Key words: training, education, extension performance

\section{A. PENDAHULUAN}

Didalam menghadapi ASEAN Community, negara-negara berkembang dituntut untuk meningkatkan daya saing di setiap sektor. Salah satu sektor yang menjadi terpenting adalah pembangunan di sektor pertanian. Oleh karena itu, dalam upaya pembangunan pertanian, pemerintah setiap tahunnya selalu menempatkan komoditas tanaman pangan sebagai hal utama dalam setiap perencanaan pembangunan pertanian. Sejalan dengan kebijakan tersebut, pembangunan pertanian selain untuk mengembangkan sistem pertanian berkelanjutan juga bertujuan untuk meningkatkan kualitas sumber daya manusia. Sumber daya manusia adalah faktor yang paling utama bagi organisasi dalam usahanya untuk mencapai tujuan organisasi. Agar dapat memperoleh sumber daya manusia yang berkualitas maka sumber daya manusia itu harus dikelola dengan baik dan benar.Kerena pengelolaan yang baik dan benar akan menghasilkan sumber daya manusia yang berkualitas dan sumber daya manusia yang berkualitas akan memiliki kinerja yang baik sehingga dapat mendukung organisasi dalam mencapai tujuannya.

Kegiatan penyuluhan pertanian secara umum dipahami sebagai kegiatan menyebarluaskan informasi pertanian serta membimbing usaha tani terhadap petani (Subejo 2013). Undang-Undang No.16 tahun 2006 menyatakan bahwa tujuan pengaturan sistem penyuluhan meliputi pengembangan sumber daya manusia dan peningkatan modal sosial, yaitu diantaranya memberdayakan pelaku utama dan pelaku usaha dalam peningkatan kemampuan melalui penciptaan iklim usaha yang kondusif, penumbuhan motivasi, pengembangan potensi, pemberian peluang, peningkatan kesadaran, dan pendampingan serta fasilitas. Hal ini memperjelas bahwa pentingnya peran penyuluh untuk meningkatkan pengetahuan dan keterampilan petani dalam aktivitas bertaninya.

Badan Ketahanan Pangan dan Pelaksana Penyuluh Pertanian, Perikanan dan Kehutanan (BKP5K) instansi Pemerintah Daerah Kabupaten Bogor yang bergerak dalam bidang ketahanan pangan dan pelaksana penyuluh pertanian, perikanan, dan kehutanan. Sebagai organisasi pemerintah 
daerah, BKP5K memiliki tugas pokok untuk membantu bupati dalam melaksanakan urusan pemerintah daerah dibidang penyelenggaraan penyuluhan pertanian, perikanan dan kehutanan. Oleh sebab itu, diperlukan adanya upaya pengembangan kapasitas penyuluh yang dimaksudkan untuk mengembangkan kemampuan penyuluh agar senantiasa dapat sejalan dengan perkembangan tugas pokok dan fungsinya dalam menyelesaikan pekerjaan yang diembannya. Saat ini, kinerja penyuluh pada BKP5K Kabupeten Bogor masih terdapat kendala-kendala yang dihadapi. Pada dasarnya hambatan terbesar kinerja penyuluh BKP5K Kabupaten Bogor terletak pada individu dan kemampuan penyuluh itu sendiri. Ini berdasarkan hasil observasi peneliti sementara ditemukan bahwa kurang maksimalnya pemberian informasi dan pengetahuan penyuluh pertanian mengenai teknologi baru pertanian kepada petani sehingga penerapan inovasi teknologi baru kurang berhasil. Hal ini sesuai dengan hasil penelitian Suryantini (2004) yang menyatakan bahwa kualitas dan kinerja penyuluh Kabupaten Bogor akan informasi teknologi pertanian tergolong rendah yang disebabkan rendahnya motivasi penyuluh pertanian untuk mencari informasi teknologi pertanian di luar lingkungan kerja. Hal ini juga dapat dilihat dari laju peningkatan produksi padi sawah di Kabupaten Bogor masih relatif rendah, penurunan rata-rata produksi padi sawah selama tahun 2011 dan 2014 terakhir mencapai 1373.7 ton, yakni dari rata-rata produksi sekitar 10431.90 ton pada tahun 2011 menjadi 9058.20 ton pada tahun 2014 (Badan Pusat Statistika 2016).

Oleh karena itu untuk mengatasi permasalahan tersebut, salah satu cara yang dapat dilakukan Badan Ketahanan Pangan dan Pelaksana Penyuluh Pertanian, Perikanan dan Kehutanan (BKP5K) Kabupaten Bogor adalah dengan melakukan pelatihan dan pendidikan bagi para penyuluh pertanian. Atas dasar itu, penelitian ini menganalisis pengaruh pelatihan dan pendidikan terhadap kinerja penyuluh pertanian di BKP5K Kabupaten Bogor. Penelitian ini bertujuan untuk: 1) menganalisis pengaruh pelatihan dan pendidikan terhadap kinerja penyuluh pertanian di BKP5K Kabupaten Bogor; dan 2) menganalisis indikator-indikator yang dominan mencerminkan keberhasilan pelatihan dan pendidikan yang diberikan kepada para penyuluh pertanian.

\section{B. Metode Penelitian}

Lokasi penelitian ini adalah di BKP5K Kabupaten Bogor J1. Letjen Ibrahim, Kelurahan Sindang Barang, Kecamatan Bogor Barat. Lokasi penelitian dipilih secara sengaja dengan pertimbangan bahwa lokasi tersebut sering dilaksanakan acara pameran hasil pertanian sehingga mempermudah proses memperoleh data responden dengan cara meninjau langsung pada saat dilaksanakan pameran hasil pertanian di BKP5K Kabupaten Bogor dan menyebaran angket kepada para responden yang dibuat dalam bentuk pernyataan yang bersifat terbuka dan tertutup. Penelitian dilakukan pada bulan Januari-Juni 2017 dengan menggunakan kuesioner, wawancara mendalam, dan pengamatan. Populasi penelitian adalah penyuluh pertanian PNS di BKP5K. Penarikan sampel berdasarkan teknik nonprobability sampling di mana pengumpulan informasi dan pengetahuan dari responden menggunakan cara sengaja (purposive sampling method) terhadap 99 penyuluh pertanian PNS. Penentuan jumlah sampel menggunakan rumus Slovin (Prasetyo 2005), dan diperoleh jumlah sempel 79 penyuluh pertanian PNS. Analisis data dilakukan secara analisis statistik deskriptif dan analisis regresi. Dalam penelitian ini, variabel bebas adalah pelatihan $\left(\mathrm{X}_{1}\right)$ dan pendidikan $\left(\mathrm{X}_{2}\right)$ dan variabel terikat adalah prestasi kerja (Y). Model tersebut dapat dilihat pada gambar sebagai berikut: 


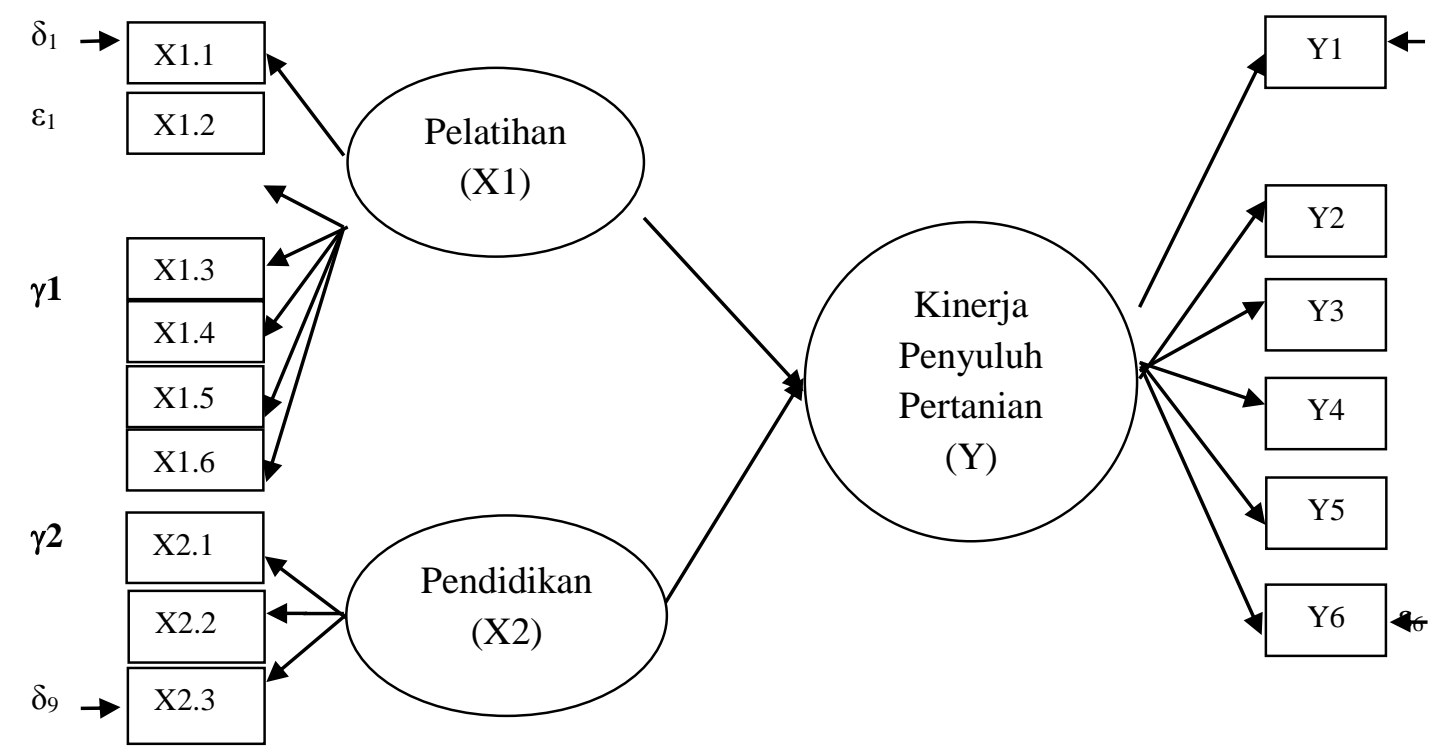

Gambar 1 Diagram alur penelitian

Keterangan:

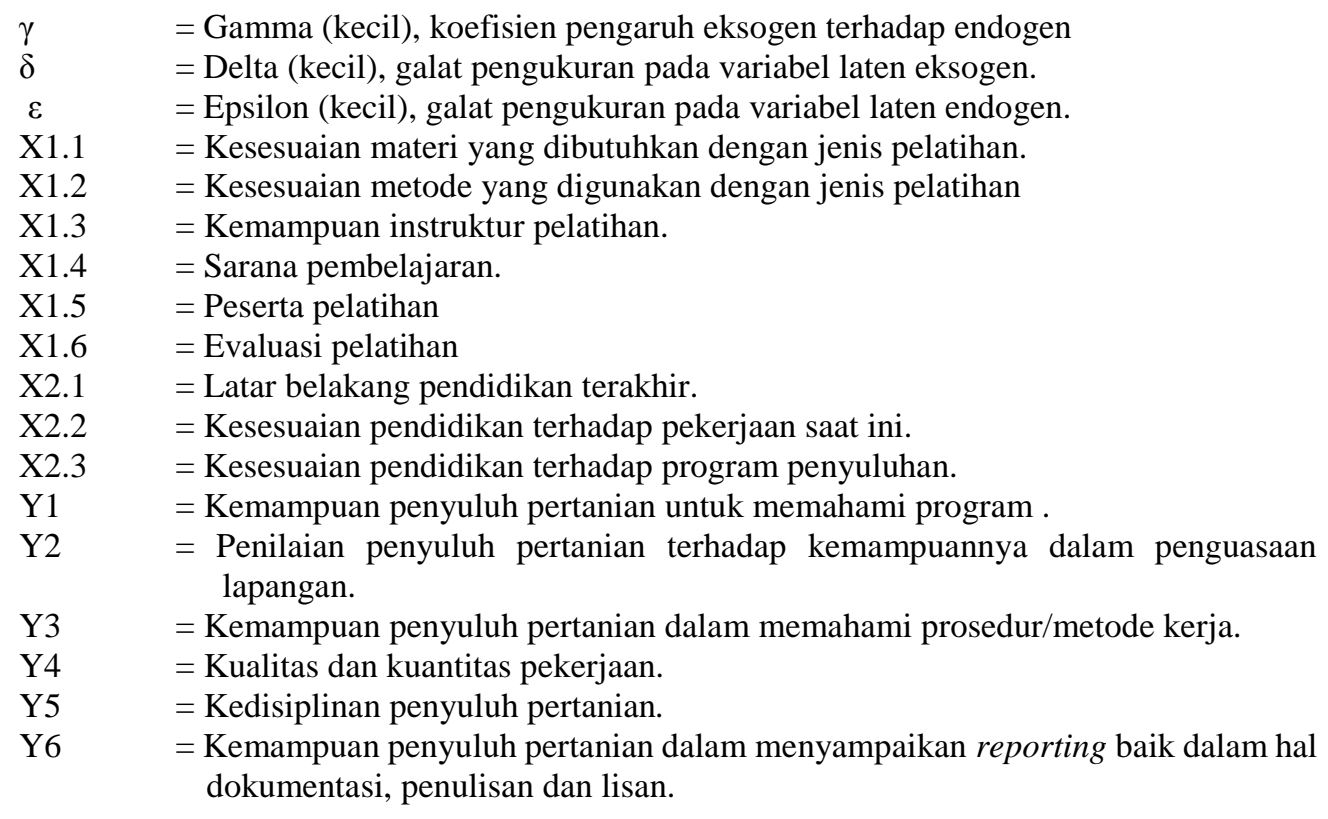

\section{Hasil Penelitian dan Pembahasan}

Tabel 1 Karakteristik responden berdasarkan jenis kelamin, usia, status, tingkat pendidikan, dan lama bekerja

\begin{tabular}{cccc}
\hline Karakteristik & Jumlah & Persentase \\
\hline Jenis kelamin & Perempuan & 36 & $36 \%$ \\
& Laki-laki & 64 & $64 \%$ \\
\hline
\end{tabular}




\begin{tabular}{|c|c|c|c|}
\hline \multirow[t]{4}{*}{ Usia } & $<=30$ th & 6 & $6 \%$ \\
\hline & $31-40$ th & 29 & $29 \%$ \\
\hline & $41-50$ th & 12 & $12 \%$ \\
\hline & $>50$ th & 53 & $53 \%$ \\
\hline \multirow{3}{*}{$\begin{array}{l}\text { Status } \\
\text { pernikahan }\end{array}$} & Menikah & 89 & $89 \%$ \\
\hline & Belum & & \\
\hline & Menikah & 11 & $11 \%$ \\
\hline \multirow{2}{*}{$\begin{array}{l}\text { Status } \\
\text { kepegawaian }\end{array}$} & PNS & 53 & $53 \%$ \\
\hline & Honorer & 47 & $47 \%$ \\
\hline \multirow{4}{*}{$\begin{array}{r}\text { Pendidikan } \\
\text { terakhir }\end{array}$} & SMA & 7 & $7 \%$ \\
\hline & D3 & 29 & $29 \%$ \\
\hline & S1 & 63 & $63 \%$ \\
\hline & S2 & 1 & $1 \%$ \\
\hline \multirow[t]{4}{*}{ Lama bekerja } & $<=10$ th & 21 & $21 \%$ \\
\hline & $11-20$ th & 20 & $20 \%$ \\
\hline & $21-30$ th & 20 & $20 \%$ \\
\hline & $>30$ th & 39 & $39 \%$ \\
\hline
\end{tabular}

Responden dalam penelitian ini berjumlah 79 responden. Informasi karakteristik responden diperoleh dari kuesioner yang telah diisi oleh para responden yang merupakan penyuluh pertanian di BKP5K Kabupaten Bogor. Karakteristik responden dapat dilihat pada tabel 1.

Berdasarkan kuesioner yang telah diisi oleh para responden, persentase jenis kelamin responden laki-laki sebesar $70.89 \%$ dan perempuan sebesar $29.11 \%$. Responden laki-laki mendominasi persentase karena mayoritas penyuluh pertanian di BKP5K Kabupaten Bogor adalah laki-laki. Usia responden yang memiliki persentase paling tinggi adalah usia lebih dari 50 tahun yaitu sebesar $59.50 \%$. Hal ini disebabkan sedikitnya pelaksanaan rekrutmen CPNS penyuluh pertanian yang baru dalam beberapa tahun terakhir, dapat dilihat hanya ada 5.06\% (4 responden yang berusia dibawah 30 tahun menjabat sebagai penyuluh PNS).

Mayoritas responden (62.03\%) memiliki pendidikan S1 sebagai pendidikan terakhir responden. Hal ini disebabkan sebagian besar responden mendapatkan kesempatan untuk mengenyam pendidikan dari SMA sampai S1 seiring dengan lamanya bekerja penyuluh pertanian tersebut. Berdasarkan hasil persentasi lama bekerja yang memiliki persentase paling tinggi adalah lama bekerja lebih dari 30 tahun yaitu sebesar $44.30 \%$.

Hasil Analisis Regresi dan Koefisien Determinasi

Tabel 2 Hasil analisis regresi linier dan koefisien determinasi 


\begin{tabular}{|c|c|c|c|c|c|c|}
\hline \multicolumn{7}{|c|}{ Coefficients $^{\mathbf{a}}$} \\
\hline \multirow{2}{*}{\multicolumn{2}{|c|}{ Model }} & \multicolumn{2}{|c|}{ Unstandardized Coefficients } & \multirow{2}{*}{$\begin{array}{c}\begin{array}{c}\text { Standardized } \\
\text { Coefficients }\end{array} \\
\text { Beta }\end{array}$} & \multirow[b]{2}{*}{$\mathrm{t}$} & \multirow[b]{2}{*}{ Sig. } \\
\hline & & $\mathrm{B}$ & Std. Error & & & \\
\hline \multirow[t]{3}{*}{1} & (Constant) & 46.384 & 9.774 & & 4.746 & .000 \\
\hline & pelatihan & -.364 & .160 & -.280 & -2.278 & .026 \\
\hline & pendidikan & .373 & .106 & .433 & 3.519 & .001 \\
\hline
\end{tabular}

a. Dependent Variable: kinerja

Dilihat dari tabel koefisien, persamaan untuk regresi linear $Y=a+b X$, yaitu $Y=46.384-0,364$ $\mathrm{X} 1+0,373 \mathrm{X} 2$. Dalam tabel ini juga menunjukkan bahwa pelatihan dan pendidikan hasil yang diperoleh masing - masing sebesar 0,026 dan 0,001, hasilnya kurang dari 0,05 yang artinya terdapat pengaruh antara pelatihan dan pendidikan terhadap kinerja penyuluh pertanian. Dari persamaan regresi linear tersebut menunjukkan ketika X1 naik satu satuan maka akan menurunkan Y sebesar 0,364 satuan dengan asumsi cateris paribus, X1 berpengaruh signifikan dilihat dari $p$ value $(0,010)<$ alpha 5\%. Begitu juga ketika X2 naik satu satuan maka akan meningkatkan Y sebesar 0,373 satuan dengan asumsi cateris paribus, $\mathrm{X} 2$ berpengaruh significant dilihat dari $\mathrm{p}$ value $(0,000)<$ alpha $5 \%$.

Model Summary

\begin{tabular}{|l|r|r|c|c|}
\hline Model & \multicolumn{1}{|c|}{$\mathrm{R}$} & R Square & \multicolumn{1}{|c|}{$\begin{array}{c}\text { Adjusted R } \\
\text { Square }\end{array}$} & $\begin{array}{l}\text { Std. Error of the } \\
\text { Estimate }\end{array}$ \\
\hline 1 & $.379^{\mathrm{a}}$ & .143 & .121 & 20.63295 \\
\hline
\end{tabular}

a. Predictors: (Constant), pendidikan, pelatihan

Besarnya nilai adjusted $\mathrm{R}^{2}$ sebesar 0.121 artinya bahwa $12,1 \%$ kinerja penyuluh dipengaruhi oleh variabel X1 dan X2. Sedangkan 87,9\% (100\% - 12,1\%) karena faktor-faktor lainnya yang tidak dimasukkan dalam model regresi.

\section{Hasil Uji simultan (F test)}

\begin{tabular}{|rr|r|r|r|r|r|}
\hline \multicolumn{1}{|c|}{ MNOVA $^{\mathbf{b}}$} \\
\hline 1 & Sum of Squares & df & Mean Square & \multicolumn{1}{c|}{ F } & \multicolumn{1}{c|}{ Sig. } \\
\hline & Regression & 5417.529 & 2 & 2708.764 & 6.363 & $.003^{\mathrm{a}}$ \\
& Residual & 32354.623 & 76 & 425.719 & & \\
& Total & 37772.152 & 78 & & & \\
\hline
\end{tabular}

a. Predictors: (Constant), pendidikan, pelatihan

b. Dependent Variable: kinerja

Pengujian uji simultan (uji F) dilakukan dengan cara membandingkan antara nilai signifikansi $\mathrm{F}$ dengan level signifikansi $(\alpha)$ dengan nilai $\alpha=0,05$. Jika signifikansi $\mathrm{F} \leq 0,05$, maka H0 ditolak dan Ha diterima. Begitu juga sebaliknya, apabila signifikansi $\mathrm{F}>0,05$, maka H0 diterima dan Ha ditolak. Dari uji ini dapat dilihat pada nilai F test sebesar 6.363 dengan tingkat signifikan 0,003 yang berarti variabel pelatihan dan pendidikan secara simultan mempengaruhi variabel kinerja penyuluh pertanian. 


\section{Hasil Analisis Statistik Deskriptif}

Tabel 3 Tabel analisis statistik deskripsi

\begin{tabular}{|c|c|c|c|c|c|c|c|c|}
\hline \multicolumn{2}{|c|}{ Variabel } & STS & TS & $S$ & SS & Total & Modus & Rerata \\
\hline \multirow[t]{6}{*}{ Pelatihan } & $\mathrm{X} 1.1$ & 3 & 1 & 46 & 29 & 79 & 3 & 3.28 \\
\hline & X1.2 & 1 & 2 & 61 & 15 & 79 & 3 & 3.14 \\
\hline & $\mathrm{X} 1.3$ & 3 & 4 & 52 & 20 & 79 & 3 & 3.13 \\
\hline & X1.4 & 3 & 13 & 54 & 9 & 79 & 3 & 2.87 \\
\hline & $\mathrm{X} 1.5$ & 2 & 5 & 54 & 18 & 79 & 3 & 3.11 \\
\hline & X1.6 & 2 & 4 & 58 & 15 & 79 & 3 & 2.95 \\
\hline \multirow[t]{3}{*}{ Pendidikan } & $\mathrm{X} 2.1$ & 1 & 8 & 40 & 30 & 79 & 3 & 3.25 \\
\hline & $\mathrm{X} 2.2$ & 1 & 2 & 50 & 26 & 79 & 3 & 3.28 \\
\hline & $\mathrm{X} 2.3$ & 0 & 5 & 56 & 18 & 79 & 3 & 3.16 \\
\hline \multirow[t]{6}{*}{ Kinerja } & Y1 & 0 & 4 & 53 & 29 & 79 & 3 & 3.23 \\
\hline & $\mathrm{Y} 2$ & 0 & 10 & 54 & 15 & 79 & 3 & 3.06 \\
\hline & Y3 & 3 & 17 & 50 & 9 & 79 & 3 & 2.82 \\
\hline & Y4 & 0 & 2 & 61 & 16 & 79 & 3 & 3.18 \\
\hline & Y5 & 0 & 5 & 60 & 14 & 79 & 3 & 3.11 \\
\hline & Y6 & 0 & 3 & 67 & 9 & 79 & 3 & 3.08 \\
\hline
\end{tabular}

$\mathrm{N}=79$

Dari tabel statistik deskriptif ini dapat dilihat indikator-indikator yang dominan mencerminkan keberhasilan pelatihan, pendidikan, dan kinerja penyuluh pertanian dengan cara membandingkan antara nilai mean setiap indikator pada masing-masing variabel. Indikator yang dominan dari variabel pelatihan terdapat pada indikator satu, yaitu kesesuaian materi yang dibutuhkan dengan jenis pelatihan sebesar 3.28 yang artinya bahwa didalam pelaksanaan pelatihan, harus memiliki kesesuaian materi yang akan diberikan terhadap kebutuhan para penyuluh pertanian. Indikator yang dominan dari variabel pendidikan terdapat pada indikator kedua, yaitu Kesesuaian pendidikan terhadap pekerjaan saat ini sebesar 3.28 yang artinya bahwa program pendidikan yang diikuti penyuluh diharapkan dapat meningkatkan pengetahuan pada pekerjaan penyuluh pertanian tersebut. Indikator yang dominan dari variabel kinerja terdapat pada indikator satu, yaitu kinerja penyuluh pertanian untuk memahami program sebesar 3.23.

\section{KESIMPULAN}

Bahwa pengaruh pelatihan di Badan Ketahanan Pangan dan Pelaksana Penyuluh Pertanian, Perikanan dan Kehutanan (BKP5K) Kabupaten Bogor berpengaruh negatif terhadap kinerja penyuluh. Ini dapat dilihat dari koefisien regresi yang bernilai negatif sebesar $-0,364$. Hal ini membuktikan bahwa pelatihan yang diberikan tidak sesuai dengan kebutuhan para penyuluh pertanian sehingga tidak mampu meningkatkan kinerja. Oleh karena itu, sebelum memberikan pelatihan sebaiknya dilakukan analisis kebutuhan dari para penyuluh pertanian. Variabel pendidikan memiliki koefisien regresi positif sebesar 0,373 yang artinya bahwa dengan 
memberikan kesempatan mendapatkan program pendidikan lanjutan kepada para penyuluh pertanian maka mampu meningkatkan kinerja penyuluh pertanian tersebut.

\section{DAFTAR PUSTAKA}

E.

Aprinto dan Jacob. 2013. Pedoman Lengkap Profesional SDM Indonesia. Jakarta (ID): Penerbit $P P M$.

Hasibuan, MSP. 2010. Manajemen Sumber Daya Manusia. Yogyakarta (ID): Andi Offset.

Lucie, S. 2005. Teknik Penyuluhan dan Pemberdayaan Masyarakat. Bogor (ID): Penerbit Ghalia Indonesia.

Rivai dan Basri. 2005. Performance Appraisal. Jakarta (ID): PT. Raja Grafindo Persada.

Subejo. 2013. Pembangunan Pertanian dan Pedesaan. Jakarta (ID): Penerbit Universitas Indonesia (UI-Press)

Suryantini. 2004. Pemanfaatan Informasi Teknologi Pertanian oleh Penyuluh Pertanian (Kasus di Kabupaten Bogor, Jawa Barat). Jurnal Perpustakaan Pertanian. Volume (13):17-23.

Wijanto. 2008. Structural Equation Modeling dengan Lisrel 8.8 Konsep dan Tutorial. Yogyakarta (ID). Graha Ilmu.

Yamin dan Kurniawan. 2009. Structural Equation Modelling: Belajar Lebih Mudah Teknik Analisis Data Kuesioner dengan LISREL-PLS. Jakarta (ID): Salemba Infotek. 